\title{
Effects of test conditions on shear behaviour of composite soil
}

1 Yanrong Li MPhil, PhD, MICE State Key Laboratory of Geohazard Prevention and Geoenvironment Protection, Chengdu, China; Key Laboratory of Karst Environment and Geohazard Prevention, Ministry of Education, Guiyang, China

2 Lung S. Chan MSC, PhD Professor, Department of Earth Sciences, The University of Hong Kong, China
3 Albert T. Yeung MSc, PhD, FICE, FHKIE, FASCE, CEng, RPE(Civil, Environmental, Geotechnical), PE Associate Professor, Department of Civil Engineering, The University of Hong Kong, China

4 Xiqiong Xiang MPhil, PhD Key Laboratory of Karst Environmental and Geohazard Prevention, Guizhou University, China
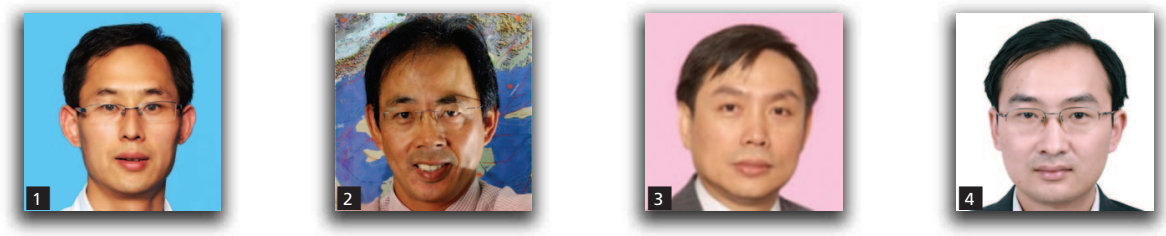

Test conditions, such as shearing rate and normal stress, have been long recognised as influencing the measured shear strength of clays and sands. However, their influence on composite soils, which have a wide range of particle sizes, has attracted much less attention from researchers. In this study, a total of 35 direct shear tests at different shearing rates under different normal stresses were conducted on specimens prepared by mixing different proportions of kaolin and glass beads. The changes in volume and water content of sheared specimens and the mesostructure of shear surfaces were studied. The results reveal a positive correlation between volume change and deviation of water content between the shear zone and outer zones, suggesting that the shear-induced volume change occurred primarily in the shear zones. Moreover, high normal stress and low shearing rate produced a relatively small void ratio in the shear zones, facilitating volumetric contraction of the specimen and the development of polished and evenly slickensided shear surfaces. In addition, the residual friction angle of the specimens tested was found to decrease with the increase in normal stress. The high shearing rate caused an increase in residual strength in specimens with low fines fraction, and reduced it in specimens with high fines fraction.

\section{Notation}

$A_{\mathrm{I}} \quad$ initial contact area

$B \quad$ pore pressure coefficient

$K \quad$ empirical coefficient in Equation 1

$\left(1-m_{\mathrm{r}}\right) \quad$ slope of line of $\log \left(\tan \left[\phi_{\mathrm{R}}^{\prime}\right]_{\mathrm{S}} /\left[\phi_{\mathrm{R}}^{\prime}\right]_{\mathrm{S}}^{\mathrm{p}}\right)$ against $\log \left(\sigma_{\mathrm{p}}^{\prime} / \sigma_{\mathrm{n}}^{\prime}\right)$

$W \quad$ width of soil specimen perpendicular to shearing direction

$\gamma \quad$ vertical displacement

$\delta \quad$ deviation of water content

$\delta_{\mathrm{h}} \quad$ horizontal displacement

$\sigma \quad$ normal stress

$\sigma_{\mathrm{n}}^{\prime} \quad$ effective normal stress

$\sigma_{\mathrm{p}}^{\prime} \quad$ pre-consolidated pressure

$\tau \quad$ shear stress

$\tau_{\mathrm{i}} \quad$ measured shear strength

$\tau_{\mathrm{R}} \quad$ residual shear strength

$\phi_{\mathrm{R}} \quad$ residual friction angle
$\left[\phi_{\mathrm{R}}^{\prime}\right]_{\mathrm{s}} \quad$ secant residual friction angle

$\left[\phi_{\mathrm{R}}^{\prime}\right]_{\mathrm{s}}^{\mathrm{p}} \quad$ secant residual friction angle at $\sigma_{\mathrm{n}}^{\prime}=\sigma_{\mathrm{p}}^{\prime}$

\section{Introduction}

Understanding of the effects of shearing rate on the constitutive behaviour of soil is crucially important for accurate interpretation and application of laboratory test results, and also for the need to accelerate commercial testing procedures to reduce costs (Kakou et al., 2001; Skempton and Petley, 1967). Since the early 1960s, many investigations in soil and rock mechanics have focused on this particular dependence. However, the reported effects of shearing rates on residual shear strength are highly controversial (Bernander et al., 1985; Horn and Deere, 1962; Idriss, 1985; La Gatta, 1970; Lemos, 1986; Li and Aydin, 2010; Martins, 1983; Parathiras, 1994; Suzuki et al., 2001; Tika, 1989). Basing on strain-controlled reversal direct shear tests on London clay, Petley (1966) reported a minimal increase $(\sim 4 \%)$ of the residual shear strength when the shearing rate was 
increased from $4 \times 10^{-5}$ to $11.0 \mathrm{~mm} / \mathrm{min}$. However, Skempton (1985) indicated negligible changes in residual shear strength in clays sheared at rates between 0.002 and $0.01 \mathrm{~mm} / \mathrm{min}$. For granular materials, Hungr and Morgenstern (1984) found that the residual shear strength of granular soils (sand and polystyrene beads) was independent of shearing rate. Sassa (1985) also concluded that the residual shear strength of granular materials was not affected by the rate of displacement, based on large-ring shear test results on glass beads. The results of work by Garga (1970), Kenney (1967), La Gatta (1970) and Cullen and Donald (1971), however, suggested an increase in residual shear strength of clayey soils with increase in shearing rate. Townsend and Gilbert (1974) reported that the residual shear strength of clays at a shearing rate of $14.6 \mathrm{~mm} / \mathrm{min}$ was $24 \%$ higher than that $0.0145 \mathrm{~mm} / \mathrm{min}$. Suzuki et al. (2001) also indicated the existence of a positive correlation between residual shear strength and shearing rate in kaolin, based on ring shear test results at shearing rates ranging from 0.02 to $2.0 \mathrm{~mm} / \mathrm{min}$. In contrast to these findings, De Beer (1967) found that the use of a lower shearing rate of $0.395 \mathrm{~mm} / \mathrm{h}$ actually resulted in a higher residual shear strength relative to the higher rate of $2.1 \mathrm{~mm} / \mathrm{h}$ for Boom clay. He attributed the increase in residual shear strength to the recovery of strength in the shear zone when the soil was sheared at a significantly slow rate. Bernander et al. (1985) also reported a decrease in residual shear strength with an increase in shearing rate in a study on the failure mechanism of rapid landslides.

The varying test results obtained for the relationship between the shearing rate and the residual shear strength of soil could plausibly be due to material texture and modes of shear deformation. Based on ring shear tests on artificial mixtures of medium sand and powdered mica, Lupini et al. (1981) reported observations on shear surfaces, and proposed three modes of residual shear behaviour: sliding, transitional and turbulent. They attributed the differential effects of shearing rates on residual shear strength to the shear mode, which is controlled by particle shape and the coefficient of interparticle friction. Specifically, the residual shear strength of soils would increase with shearing rate for the sliding shear mode and decrease for the turbulent shear mode. Lemos et al. (1985) reported that the residual shear strength of soils of high clay fraction ( $\geqslant 50 \%$ weight) increased and that of soils with low clay fraction (5-50\%) decreased with an increase in shearing rate, whereas soils with a clay content less than $5 \%$ were not affected by the shearing rate. Lemos (1986) attributed the positive shearing rate effect to disturbance of the shear zone by massive particles, and the negative rate effect to an increase in porosity and water content in the shear zone. Parathiras (1994) argued that the effects of shearing rate were dependent on plasticity index and clay fraction, as he observed that the negative shearing rate effects occurred only in non-plastic soils. Tika (1989) and Tika and Hutchinson (1999) suggested that the effects of shearing rate on residual shear strength were dependent more upon a combination of factors, such as the shear mode (sliding, transitional and turbulent), level of normal stress and soil index properties (clay fraction and plasticity), rather than on any particular factor alone.

Skempton and Petley (1967) indicated that the envelope of residual shear strength of London clay appeared to be non-linear when sheared under low normal stress $(\leqslant 50 \mathrm{kPa})$. Based on the results of reversal direct shear tests on natural soils, Kenney (1967) observed that the residual shear strengths of natural soils were dependent on the magnitude of the effective normal stress. Townsend and Gilbert (1973) argued that the residual shear strength of clay shales was not affected by an effective normal stress greater than $150 \mathrm{kPa}$, based on results obtained from reversal direct shear and ring shear tests. Chattopadhyay (1972) put forward a non-linear relationship between effective normal stress $\sigma_{\mathrm{n}}^{\prime}$ and residual friction angle $\phi_{\mathrm{R}}$ as

$$
\text { 1. } \tan \phi_{\mathrm{R}}=\frac{K \tau_{\mathrm{i}}}{\sqrt[3]{\sigma_{\mathrm{n}}^{\prime}}}
$$

where $\tau_{\mathrm{i}}$ is the measured shear strength, and $K$ is an empirical coefficient. The results from drained ring shear tests on clay and clay shales by Stark and Eid (1994) reveal the existence of a nonlinear drained residual shear strength envelope with a dependence on effective normal stress. Wan and Kwong (2002) also argued for a stress-dependent drained residual shear strength envelope, and suggested that the reduction of residual friction angle under higher consolidation stress was due to the fact that clay-size materials acted as gel-to-gel contacts between coarser particles. Based on an extensive study of landslides, Mesri and Shahien (2003) demonstrated a non-linear dependence of residual shear strength on effective normal stress as

2. $s(r)=\sigma_{\mathrm{n}}^{\prime} \tan \left[\phi_{\mathrm{R}}^{\prime}\right]_{\mathrm{s}}^{\mathrm{p}}\left(\frac{\sigma_{\mathrm{p}}^{\prime}}{\sigma_{\mathrm{n}}^{\prime}}\right)^{1-m_{\mathrm{r}}}$

where $s(r)$ is the residual shear strength (shear strength of presheared surfaces, from pre-cut surfaces of intact or reconstituted specimens); $\left[\phi_{\mathrm{R}}^{\prime}\right]_{\mathrm{s}}^{\mathrm{p}}$ is the secant residual friction angle at $\sigma_{\mathrm{n}}^{\prime}=\sigma_{\mathrm{p}}^{\prime} ; \quad \sigma_{\mathrm{n}}^{\prime}$ is the effective normal stress; $\sigma_{\mathrm{p}}^{\prime}$ is the preconsolidated pressure; $\left(1-m_{\mathrm{r}}\right)$ is the slope of the line of $\log \left(\tan \left[\phi_{\mathrm{R}}^{\prime}\right]_{\mathrm{S}} /\left[\phi_{\mathrm{R}}^{\prime}\right]_{\mathrm{S}}^{\mathrm{p}}\right)$ against $\log \left(\sigma_{\mathrm{p}}^{\prime} / \sigma_{\mathrm{n}}^{\prime}\right)$; and $\left[\phi_{\mathrm{R}}^{\prime}\right]_{\mathrm{S}}$ is the secant residual friction angle.

Although the shearing rate and normal stress have been recognised as influencing the measured residual shear strength of clays and sands, their influences on composite soils of a wide range of particle sizes have attracted much less attention from researchers. A systematic experimental investigation into the constitutive behaviour of mixtures of kaolin and glass beads in direct shear was therefore conducted. The particle sizes of the mixture were up to $8.0 \mathrm{~mm}$. The primary objectives were to explore the effects of shearing rate and normal stress on 
(a) changes in volume and water content during shearing

(b) the development of shear zone structure

(c) the residual shear strength of composite soils that can be mobilised.

\section{Experimental procedure}

2.1 Material characteristics and sample preparation Kaolin and non-porous soda lime glass beads were used as constituent materials to prepare the samples in the study. The glass beads were spherical in shape, with a smooth surface; they were essentially free of particle breakage during shearing under the normal stresses used in the present study, that is, $\leqslant 200 \mathrm{kPa}$. The particle sizes of the kaolin were $\leqslant 0.002 \mathrm{~mm}$, and those of the glass beads ranged from $0.063 \mathrm{~mm}$ to $8.0 \mathrm{~mm}$. The specific gravity of the glass beads was $2 \cdot 48$, and that of the kaolin was $2 \cdot 68$.

Each of the constituent materials was first dried in an oven at a temperature of $105 \pm 0 \cdot 5^{\circ} \mathrm{C}$, and then mixed and divided by the quartering method (dividing a circular heap by diameters at right angles into four equal parts, removing two diagonally opposite quarters and thoroughly mixing the two remaining quarters). In total seven samples were prepared by mixing the constituent materials at pre-specified proportions, as listed in Table 1. Each mixture was placed in a plastic bag and shaken until it was homogeneous. The particle size distributions of the samples are shown in Figure 1. Each sample was divided into five fractions as specimens to be sheared at pre-specified test conditions: normal stress 50,100 or $200 \mathrm{kPa}$, and shearing rate $0.06,0.6$ or $6.0 \mathrm{~mm} /$ $\min$.

\subsection{Test equipment}

An intermediate strain-controlled digital direct-shear apparatus, with specimen dimensions $100 \mathrm{~mm} \times 100 \mathrm{~mm} \times 40 \mathrm{~mm}$ high, was used in this study. The apparatus was equipped with two digital dial gauges to measure the vertical and horizontal (shear) displacements. Normal stress was applied to the specimen through a lever loading device. Shear force was measured by

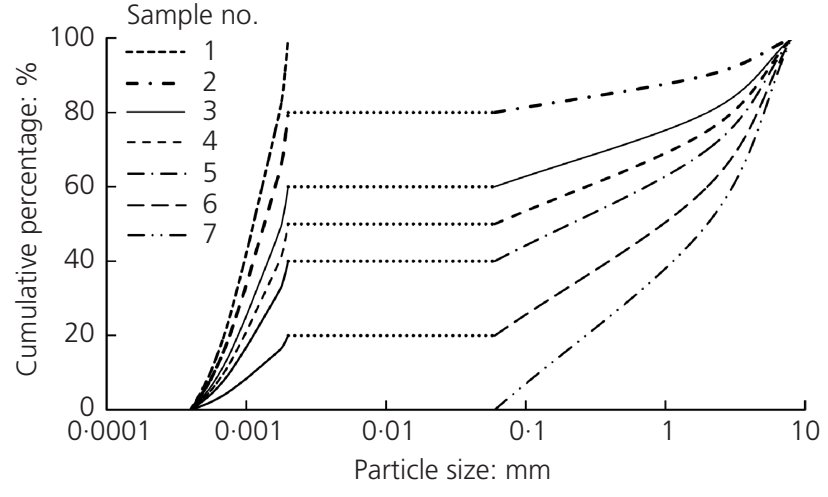

Figure 1. Particle size distribution of soil mixtures testes

means of two proving rings with measuring capacities of $2.0 \mathrm{kN}$ and $4.5 \mathrm{kN}$, and accuracy within $\pm 1 \%$ of the indicated load. The two capacities were used to measure shear force under low and high normal stress conditions respectively. Horizontal and vertical displacements, and shear force applied, were recorded by a data logger at the minimum shear displacement intervals of $2 \mu \mathrm{m}$.

\subsection{Testing procedures}

Each specimen was prepared in the shear box in three layers of equal thickness. Each layer was compacted by dropping a $2.5 \mathrm{~kg}$ hand rammer (with a square end of $10 \mathrm{~mm} \times 10 \mathrm{~mm}$ ) from a height of $450 \mathrm{~mm} 30$ times on to the dry specimen. Specimens of each sample (e.g. specimens $1-\mathrm{I}$ to $1-\mathrm{V}$ from sample 1) had the same mass, and were compacted into the same volume, to ensure a uniform dry density and void ratio, and therefore the same water content after full saturation.

Prior to the experimentation in the present study, a trial saturation test was conducted by means of a triaxial compression apparatus on a cylindrical $100 \%$ kaolin specimen $200 \mathrm{~mm}$ high and $100 \mathrm{~mm}$ in diameter. It took approximately $16 \mathrm{~h}$ for this specimen to be fully saturated with a pore pressure coefficient $B \geqslant 0.95$. As the dimensions of the test specimens in the present study $(100 \mathrm{~mm} \times 100 \mathrm{~mm} \times 40 \mathrm{~mm}$ high $)$ were much less than those

\begin{tabular}{|c|c|c|c|c|c|c|}
\hline Sample no. & Kaolin: \% & Glass beads: \% & Liquid limit: \% & Plasticity index: \% & BSCS* classification & USCS $^{\dagger}$ classification \\
\hline 1 & $100 \cdot 0$ & 0.0 & $50 \cdot 3$ & $28 \cdot 3$ & $\mathrm{CH}$ & $\mathrm{CH}$ \\
\hline 2 & $80 \cdot 0$ & $20 \cdot 0$ & $43 \cdot 8$ & $24 \cdot 0$ & $\mathrm{Cl}$ & $\mathrm{CL}$ \\
\hline 3 & $60 \cdot 0$ & $40 \cdot 0$ & $33 \cdot 8$ & $17 \cdot 5$ & CLS-CLG & $C L$ \\
\hline 4 & $50 \cdot 0$ & $50 \cdot 0$ & $27 \cdot 2$ & $12 \cdot 3$ & MLS-MLG & $C L$ \\
\hline 5 & $40 \cdot 0$ & $60 \cdot 0$ & $22 \cdot 8$ & $9 \cdot 3$ & MLS-MLG & SC \\
\hline 6 & $20 \cdot 0$ & $80 \cdot 0$ & $13 \cdot 4$ & $2 \cdot 3$ & SPG-GPS & SC \\
\hline 7 & 0.0 & $100 \cdot 0$ & - & - & GW & SW \\
\hline
\end{tabular}

* British Soil Classification System.

$\dagger$ Unified Soil Classification System. 
of the cylindrical specimen in the trial triaxial compression test, specimens made of kaolin and glass beads were immersed in water for $48 \mathrm{~h}$ and those made solely of glass beads were immersed for $24 \mathrm{~h}$ to attain full saturation. A seating pressure of $4.21 \mathrm{kPa}$ was applied on the load cap during saturation to minimise any free swell.

The saturated specimen was then consolidated under the prespecified vertical stress for approximately $24 \mathrm{~h}$. After consolidation, the upper and lower shear boxes were separated by approximately $0.2 \mathrm{~mm}$ and the specimen was sheared until a relative horizontal displacement of approximately $14 \mathrm{~mm}$ had been achieved. The data were recorded at intervals of $2 \mu \mathrm{m}$ of horizontal displacement, and the ambient temperature was maintained at $19.5 \pm 0.5^{\circ} \mathrm{C}$ during the test. Each specimen was sheared only once.

\section{Results and discussion}

The normal stress $(\sigma)$ and shear stress $(\tau)$ were calculated by dividing the measured vertical load and shear force by the contact area, assuming the stresses were distributed uniformly across the shear plane. Corrections for the changes in the contact area of the shearing plane were applied to the shear stress calculations using the equation

\section{3. $A_{\mathrm{CS}}=A_{\mathrm{I}}-\left(W \times \delta_{\mathrm{h}}\right)$}

where $A_{\mathrm{I}}$ is the initial area, $W$ is the width of the soil specimen perpendicular to the shearing direction, and $\delta_{\mathrm{h}}$ is the horizontal displacement. For normal stress, a cross-sectional area of $100 \times$ $100 \mathrm{~mm}^{2}$ was used, and was assumed to be constant during the test (Xu et al., 2007).

In this paper, the residual shear strength $\tau_{\mathrm{R}}$ refers to the shear stress in the residual state. The residual friction angle $\phi_{R}$ is derived from the residual stress ratio by

4. $\phi_{\mathrm{R}}=\tan ^{-1}\left(\frac{\tau_{\mathrm{R}}}{\sigma}\right)$

where $\sigma$ is the normal stress. The terms 'fine fraction' and 'coarse fraction' are used to refer to the percentages by weight of particles smaller than $2 \mu \mathrm{m}$ and greater than $63 \mu \mathrm{m}$ in diameter respectively. The test results, in terms of test conditions, horizontal displacement and stress ratio at the residual state, are summarised in Table 2 .

\subsection{Volume change}

The vertical displacement of the specimens at residual state are presented against the normal stress applied and the shearing rate in Figures 2(a) and 2(b) respectively. The specimens presented in Figure 2(a) were sheared at $0.06 \mathrm{~mm} / \mathrm{min}$ and those presented in Figure 2(b) were subjected to a normal stress of $200 \mathrm{kPa}$. Positive values of vertical displacement represent dilation and negative values represent contraction. Generally speaking, the results reveal a strong dependence of vertical displacement on both the normal stress and the shearing rate. As shown in Figure 2(a), samples 1 to 4 exhibited a contraction, with negative values of vertical displacement, and samples 6 and 7 exhibited a dilation. In all cases, the vertical displacement decreased with increase in normal stress. The higher the normal stress applied, the lower was the potential for the specimen to dilate. Sample 5, for example, exhibited dilation with positive vertical displacement under a normal stress of $50 \mathrm{kPa}$ (specimen 5-I), but reversed into a contraction when sheared under $100 \mathrm{kPa}$ (5-II). On the other hand, as shown in Figure 2(b), the vertical displacement increased with shearing rate. The faster the shearing rate, the greater was the potential for the specimen to dilate. For instance, sample 5 gradually transformed from contraction to dilation when the shearing rate was increased from 0.06 to $6.0 \mathrm{~mm} / \mathrm{min}$.

Mitchell (1993) attributed dilation/contraction to shear-induced change of the soil structure. Since the specimen was fully submerged during shearing, it is reasonable to assume that it remained fully saturated during shearing. Therefore, the water content of the soil reveals the void ratio, density and microstructure of the sheared specimen. To develop a better insight into the change of structure of the sheared specimen, the water content of each sheared specimen was determined immediately after removing it from the apparatus and wiping off the free water on the surfaces. A strip of specimen approximately $10 \mathrm{~mm}$ thick and $60 \mathrm{~mm}$ wide along the direction of shear was cut from the middle of the shear zone. This strip was then divided into three parts, and their average water content was taken as that of the shear zone. Two pieces, each weighing approximately $40 \mathrm{~g}$, were cut from the top and bottom layers of each sheared specimen for measurements of water content. These locations are denoted as 'outer zones'. It was observed that the water contents of the top and bottom layers were approximately the same for each specimen, with an average standard deviation of less than $0 \cdot 1 \%$. Their average was then used for comparison with the average water content of the shear zone. The water contents of the specimens of sample 7, which were composed of only the coarse fraction (glass beads), were not determined owing to the free drainage in these specimens.

The differences in water content between the shear zone and the outer zones against the normal stress applied and shearing rate are plotted in Figures 3(a) and 3(b) respectively. The specimens presented in Figure 3(a) were sheared at $0.06 \mathrm{~mm} / \mathrm{min}$ and those presented in Figure 3(b) were subjected to a normal stress of $200 \mathrm{kPa}$. Negative values indicate that the water content of the shear zone was lower than those of the outer zones, and positive values that it was higher. The distance from the data point to the neutral line, the ' 0.0 ' line, indicates the extent to which the water content of the shear zone deviated from that of the outer zones. It can be observed in Figure 3 that the difference in water content gradually decreases from positive to negative with either an 


\begin{tabular}{|c|c|c|c|c|c|c|}
\hline \multicolumn{5}{|c|}{ Test conditions } & \multicolumn{2}{|c|}{ Residual state } \\
\hline $\begin{array}{l}\text { Sample } \\
\text { no. }\end{array}$ & $\begin{array}{l}\text { Specimen } \\
\text { no. }\end{array}$ & $\begin{array}{c}\text { Normal stress, } \sigma: \\
\mathrm{kPa}\end{array}$ & $\begin{array}{c}\text { Shearing rate: } \\
\mathrm{mm} / \mathrm{s}\end{array}$ & $\begin{array}{l}\text { Dry density: } \\
\text { g/ } / \mathrm{cm}^{3}\end{array}$ & $\begin{array}{l}\text { Horizontal displacement: } \\
\text { mm }\end{array}$ & $\begin{array}{c}\text { Residual stress ratio, } \\
\tau_{\mathrm{R}} / \sigma\end{array}$ \\
\hline \multirow[t]{5}{*}{1} & $1-1$ & 50 & 0.06 & 1.52 & $3 \cdot 56$ & 0.33 \\
\hline & $1-\|$ & 100 & 0.06 & 1.52 & $5 \cdot 15$ & 0.32 \\
\hline & $1-|| \mid$ & 200 & 0.06 & $1 \cdot 54$ & $10 \cdot 63$ & 0.31 \\
\hline & 1-IV & 200 & 0.6 & 1.51 & 11.60 & 0.25 \\
\hline & $1-V$ & 200 & 6.0 & $1 \cdot 54$ & $13 \cdot 40$ & 0.28 \\
\hline \multirow[t]{5}{*}{2} & $2-1$ & 50 & 0.06 & 1.53 & 6.69 & 0.59 \\
\hline & $2-I I$ & 100 & 0.06 & 1.55 & $8 \cdot 26$ & 0.50 \\
\hline & $2-I I I$ & 200 & 0.06 & 1.57 & 8.98 & 0.45 \\
\hline & $2-I V$ & 200 & 0.6 & 1.59 & $7 \cdot 32$ & 0.43 \\
\hline & $2-V$ & 200 & $6 \cdot 0$ & 1.56 & $11 \cdot 53$ & 0.42 \\
\hline \multirow[t]{5}{*}{3} & $3-1$ & 50 & 0.06 & 1.67 & 8.85 & 0.62 \\
\hline & $3-11$ & 100 & 0.06 & 1.74 & $6 \cdot 70$ & 0.54 \\
\hline & $3-111$ & 200 & 0.06 & 1.77 & 8.61 & 0.48 \\
\hline & $3-I V$ & 200 & 0.6 & 1.80 & 9.08 & 0.44 \\
\hline & $3-V$ & 200 & $6 \cdot 0$ & $1 \cdot 78$ & 8.89 & 0.40 \\
\hline \multirow[t]{5}{*}{4} & 4-I & 50 & 0.06 & 1.77 & 8.67 & 0.62 \\
\hline & $4-I I$ & 100 & 0.06 & 1.84 & $7 \cdot 90$ & 0.59 \\
\hline & $4-|| \mid$ & 200 & 0.06 & 1.88 & $9 \cdot 75$ & 0.49 \\
\hline & 4-IV & 200 & 0.6 & 1.89 & $6 \cdot 74$ & 0.45 \\
\hline & $4-V$ & 200 & $6 \cdot 0$ & 1.85 & $9 \cdot 43$ & 0.42 \\
\hline \multirow[t]{5}{*}{5} & 5-I & 50 & 0.06 & 1.83 & 6.93 & 0.65 \\
\hline & $5-11$ & 100 & 0.06 & 1.86 & 8.06 & 0.60 \\
\hline & 5-III & 200 & 0.06 & 1.93 & $7 \cdot 90$ & 0.52 \\
\hline & 5-IV & 200 & 0.6 & 1.94 & $8 \cdot 33$ & 0.46 \\
\hline & $5-V$ & 200 & $6 \cdot 0$ & 1.91 & $12 \cdot 57$ & 0.38 \\
\hline \multirow[t]{5}{*}{6} & $6-1$ & 50 & 0.06 & 2.04 & $9 \cdot 49$ & 0.66 \\
\hline & $6-11$ & 100 & 0.06 & $2 \cdot 00$ & $9 \cdot 31$ & 0.62 \\
\hline & $6-|I|$ & 200 & 0.06 & 1.98 & 8.48 & 0.58 \\
\hline & 6-IV & 200 & 0.6 & 2.06 & $7 \cdot 57$ & 0.61 \\
\hline & $6-V$ & 200 & $6 \cdot 0$ & 1.84 & $12 \cdot 7$ & 0.61 \\
\hline \multirow[t]{5}{*}{7} & 7-I & 50 & 0.06 & $1 \cdot 76$ & $4 \cdot 39$ & 0.73 \\
\hline & $7-11$ & 100 & 0.06 & 1.75 & $3 \cdot 34$ & 0.70 \\
\hline & $7-111$ & 200 & 0.06 & 1.74 & $7 \cdot 89$ & 0.59 \\
\hline & 7-IV & 200 & 0.6 & 1.76 & $6 \cdot 34$ & 0.62 \\
\hline & $7-V$ & 200 & $6 \cdot 0$ & 1.77 & $6 \cdot 16$ & 0.65 \\
\hline
\end{tabular}

Table 2. Summary of test results

increase in normal stress or a decrease in shearing rate. This indicates that high normal stress tended to cause low water content in the shear zone, and the higher the normal stress applied during shearing, the lower was the water content of the shear zone relative to that of the outer zones. Moreover, the slower the shearing rate, the lower was the water content of the shear zone relative to that of the outer zones. For example, for sample 5, when sheared under $50 \mathrm{kPa}(5-\mathrm{I})$, the shear zone had a water content approximately $1.3 \%$ greater than that of the outer zones. When sheared under $100 \mathrm{kPa}$ (5-II), the water content of the shear zone was less than that of the outer zones. The water content of the shear zone reversed to be greater than that of the outer zones when the specimen was sheared at a high shearing rate of $6.0 \mathrm{~mm} / \mathrm{min}(5-\mathrm{V})$.

Since the specimen was fully saturated during shearing, the change in water content reflects the change in void ratio. The lower water content (negative difference) in the shear zone relative to the outer zones could suggest that the void ratio of the shear zone was less than that of the outer zones, indicating densification/contraction of the shear zone during shearing, whereas a greater water content (positive difference) could 


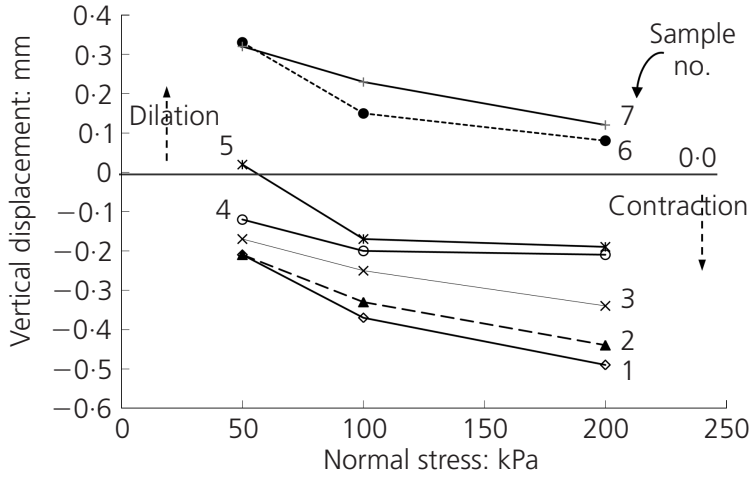

(a)

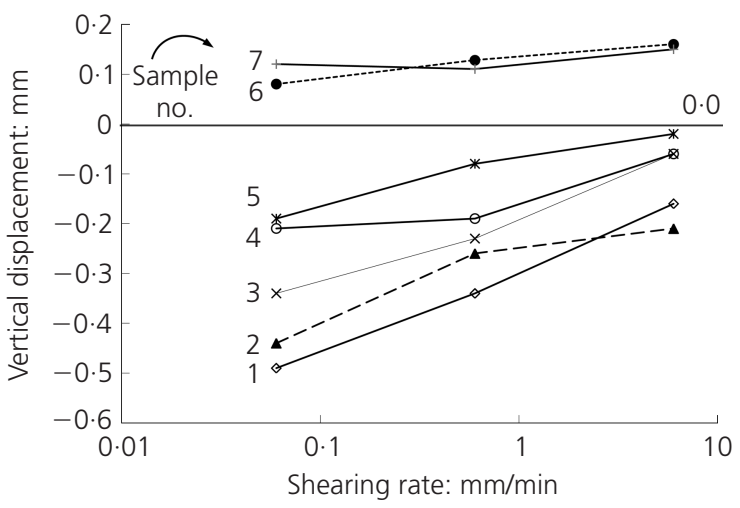

(b)

Figure 2. Plots of vertical displacement against: (a) normal stress; (b) shearing rate

suggest a loosening/dilation of the shear zone material. As shown in Figure 4, the correlation between the vertical displacement $\gamma$ and the difference $\delta$ in water content between the shear zone and outer zones can be expressed by the best-fit line

5. $\gamma=0 \cdot 166 \delta(R=0.740)$

The intercept of zero of this correlation implies that no vertical displacement (volume change) would be expected if there is no difference in water content between shear zone and outer zones. This suggests that the volumetric change of the sample was caused mainly by changes in the void ratio or structure in the shear zone. This inference agrees with the conclusion of Tatsuoka et al. (1990) and Wu et al. (2008) that during the shearing test, disturbance of the shear zone accounts for the observed bulk volume change. In other words, the most disturbed part is the shear zone, while the outer zones remain unchanged during shearing. The inference from Figure 4 together with the implication of Figure 2 makes it evident that an increase in normal stress would enhance the tendency for the shear zone to contract, by reducing both the void ratio and water content of the material in the shear zone. However, an increase in shearing rate would enhance the tendency for the shear zone to dilate, by increasing the void ratio and water content of the material in the shear zone.

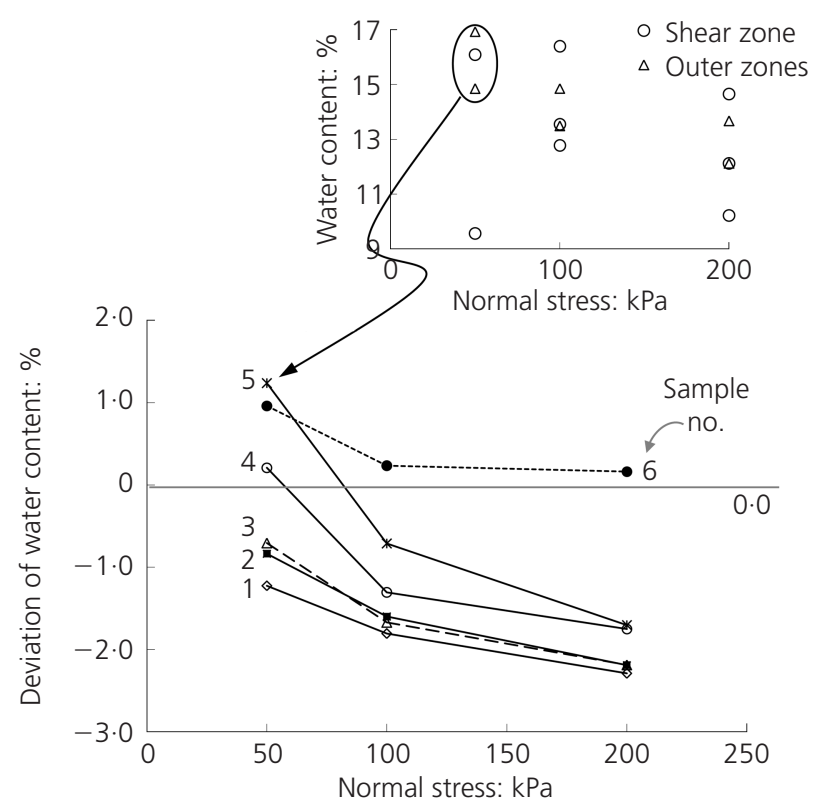

(a)

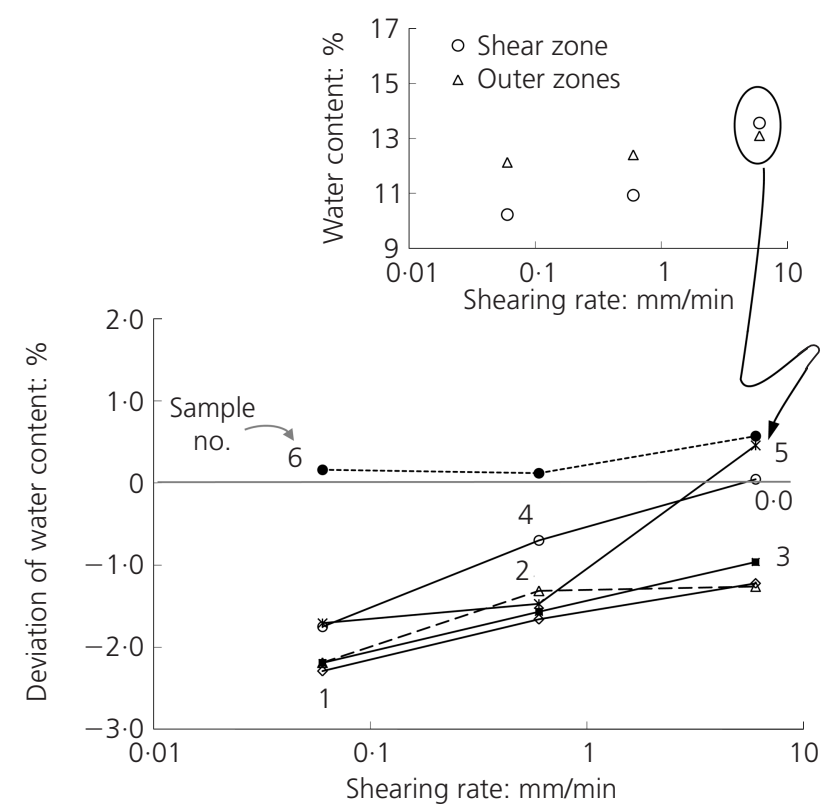

(b)

Figure 3. Differences in water content of shear zone from outer zones of sheared specimens plotted against: (a) normal stress;

(b) shearing rate

The results in Figures 2 and 4 also reveal the impact of the grain size distribution on the mechanical behaviour of the composite samples during shearing. A greater coarse fraction in the samples (e.g. samples 6 and 7) resulted in less volumetric contraction, or even dilation, whereas a smaller coarse fraction led to more volumetric contraction (e.g. samples 1, 2 and 3). This observation may plausibly be attributed to reorganisation of the soil fabric in the shear zone. When a sample of $100 \%$ fine fraction (e.g. sample 1) is sheared, a well-slickensided shear surface develops, with 


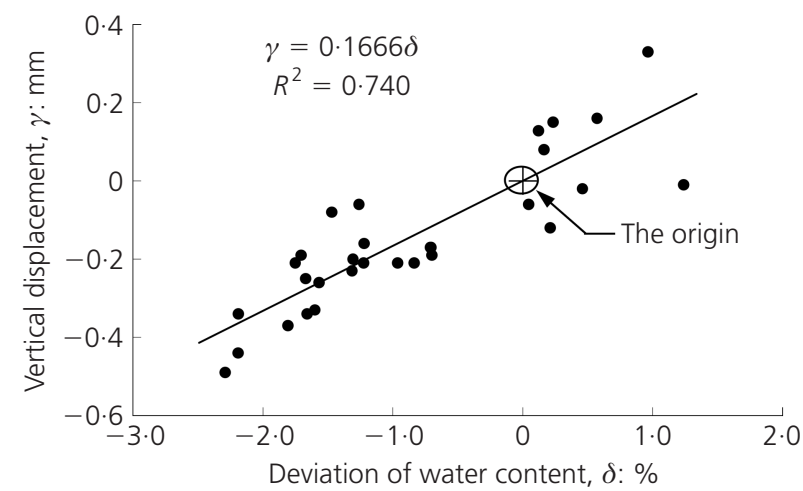

Figure 4. Linear relationship between vertical displacement and deviation of water content in shear zone from outer zones

fine particles aligned in parallel with the shearing direction. The reorientation of the fine particles causes a volumetric contraction of the sample. As the normal stress increases, a greater portion of edge-to-face interaction of platy clay particles is converted to face-to-face interaction, resulting in a strong foliated fabric, and volumetric contraction (Stark and Eid, 1994). On the other hand, when a sample with a large coarse fraction (e.g. sample 7) is sheared, the residual state is reached with volumetric dilation due to interlocking of coarse particles ( $\mathrm{Li}$ and Aydin, 2010; Taylor, 1948).

Li and Aydin (2010) argued that a high normal stress favours sparseness (large spacing between coarse particles) and penetration of coarse particles into the finer matrix, suppressing dilation of the specimen. For soil samples with appreciable fractions of both fine and coarse particles, (e.g. samples 2 to 6), the volumetric change is governed by the relative dominance of reorientation of fine particles and interlocking of coarse particles during the shearing process (Kenney, 1967; Lupini et al., 1981). If reorientation prevails, contraction occurs; if particle interlocking is dominant, dilation occurs. Thus it can be understood how the normal stress affects the mechanical behaviour of soils: a high normal stress causes more face-to-face contacts of clay particles, favouring contraction (Stark and Eid, 1994), and also causes coarse particles, when moved by shearing, to be pushed into the fine matrix, restraining dilation. For the effects of shearing rate on volumetric change, Lemos (1986) concluded that massive particles in soil disturbed the shear zone more by lifting the porosity when sheared at a high shearing rate than at a low rate. $\mathrm{Li}$ and Aydin (2010) also found that a high shearing rate favoured dilation of the specimen by preventing the coarse particles from penetrating into the fine matrix.

\subsection{Mesostructure of shear surface}

Upon completion of shearing, the sheared specimen was split into two parts for examination of the shear surfaces. As shown in Figure 5, the shear surface becomes smoother, more even and polished, and well slickensided when sheared under a higher normal stress. For sample 2, comprising $80 \%$ fines, specimens 2-I, 2-II and 2-III, which were subjected to normal stresses of $50 \mathrm{kPa}, 100 \mathrm{kPa}$ and $200 \mathrm{kPa}$ respectively during shearing, exhibited an increasingly smoother and more polished shear surface with increasing normal stress. Specimens 2-IV and 2-V were sheared at 0.6 and $6 \mathrm{~mm} / \mathrm{min}$ respectively. The former exhibited roughness and morphology similar to those of specimen 2-II, whereas the latter was relatively rough, uneven and locally disrupted by coarse particles.

Sample 3 contained a 60:40 clay: coarse fraction ratio. Specimens 3-I and 3-II had shear surfaces marked by discontinuous grooves caused by the penetration of coarse particles, whereas the shear surfaces of specimen 3-III were relatively reflective, even and slickensided. For the specimens sheared at higher shearing rates, the shear surfaces of specimen 3-IV were characterised by fluctuating slickensides. In specimen $3-\mathrm{V}$, slickensides did not spread over the entire shear surfaces. However, local congregations of coarse particles surrounded by fines were observed, causing deep grooves (or coarse striations) on the shear surface, and interrupting the slickensides.

Sample 4 contained a 1:1 fine: coarse fraction ratio. The shear surfaces of specimen 4-III revealed poorly developed and discontinuous slickensides. Specimen 4-II had several small slickensided portions scattered on the shear surfaces. There was no evidence that specimens 4-I and 4-IV contained slickensides on the shear surfaces. The shear surfaces of specimen $4-\mathrm{V}$ were not distinct, and the shear zone resembled a reworked soil mass without any shear-induced structure.

Based on the visual examination of the shear surfaces, the following inferences can be drawn.

(a) At the same shearing rate, the shear surface becomes smoother with an increase in normal stress applied during shearing.

(b) A high shearing rate prevents the development of slickensides, and produces rougher and more uneven shear surfaces.

(c) A larger fines fraction promotes the development of smoother and more polished shear surfaces.

\subsection{Residual strength}

Figure 6 shows the residual friction angle determined for the specimens at a shearing rate of $0.06 \mathrm{~mm} / \mathrm{min}$ under the three normal stresses of 50,100 and $200 \mathrm{kPa}$. In general, the residual shear strength of the soil mixtures tested was dependent on normal stress, as the residual friction angle decreased with increase in normal stress applied during shearing. Low residual shear strength is attributed to a relatively smooth and even shear surface, whereas a rough and uneven shear surface is responsible for a high residual shear strength. As shown in Figure 5, specimen 2-III (sheared under normal stress of $200 \mathrm{kPa}$ ) had the smoothest shear surfaces among specimens 2-I $(50 \mathrm{kPa})$, 2-II 


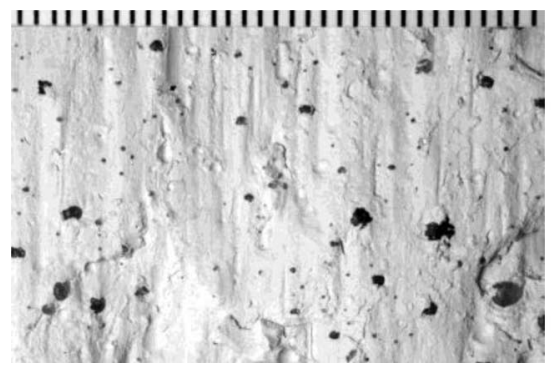

2-1

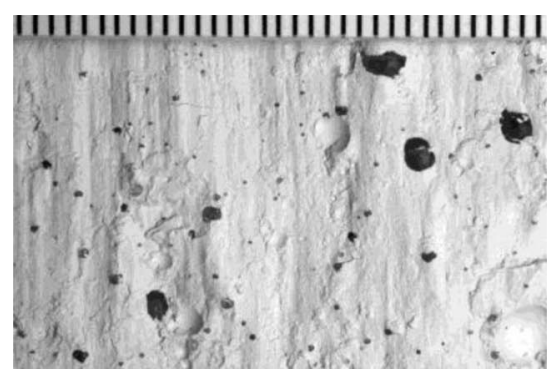

2-II

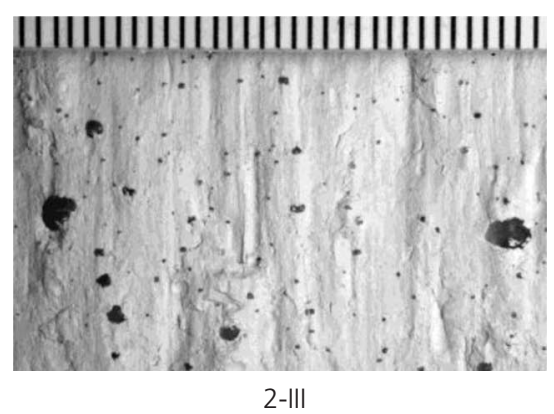

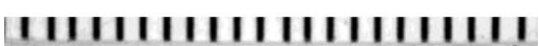

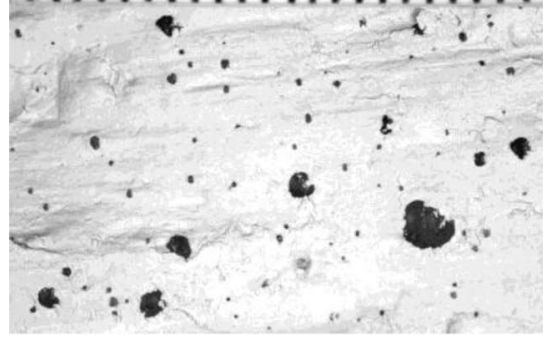

2-IV

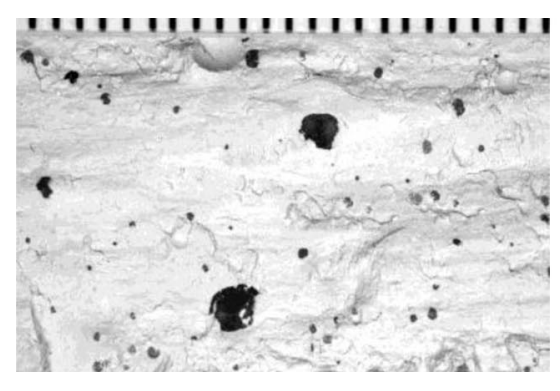

$2-\mathrm{V}$

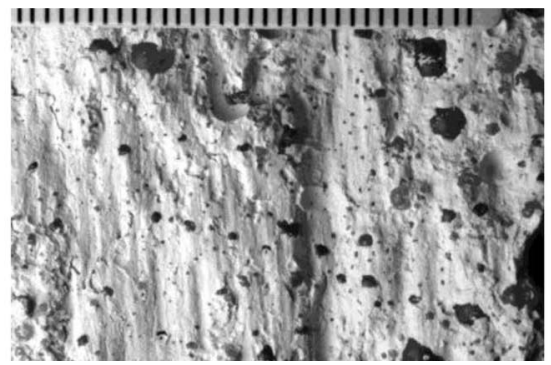

$3-1$

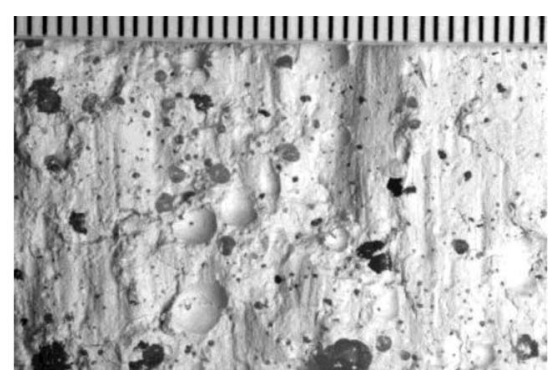

3-II

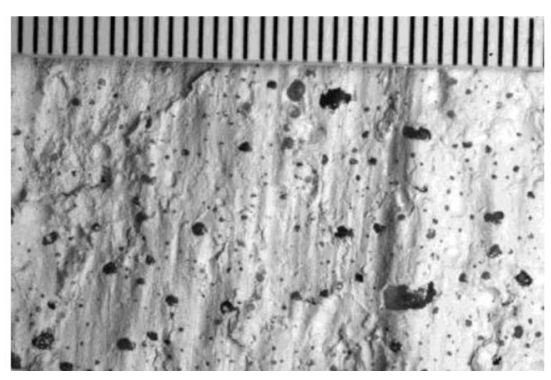

3-III

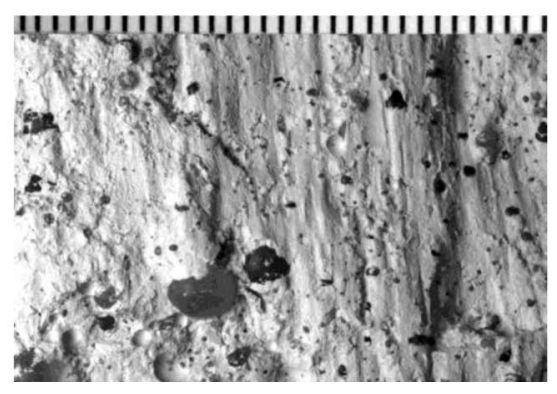

3-IV

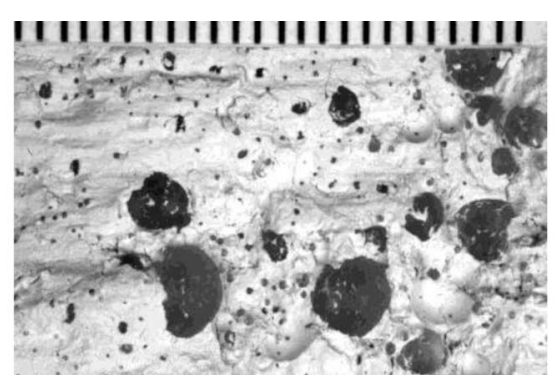

3-V

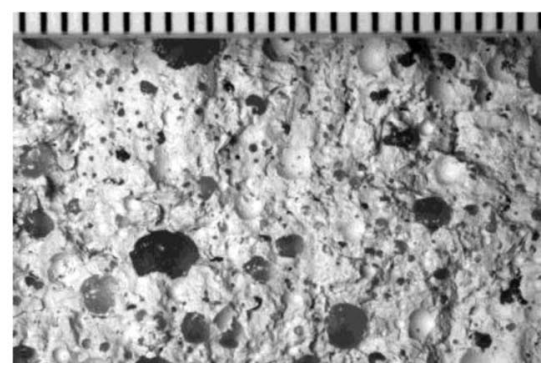

4-1

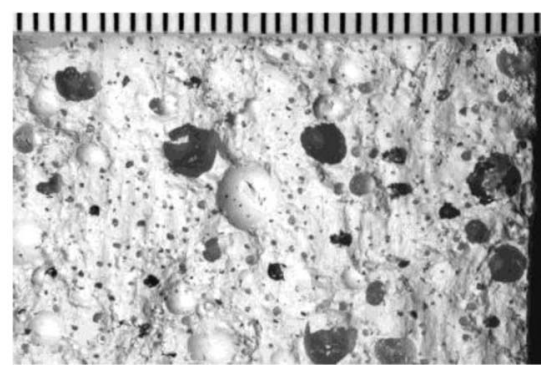

$4-||$

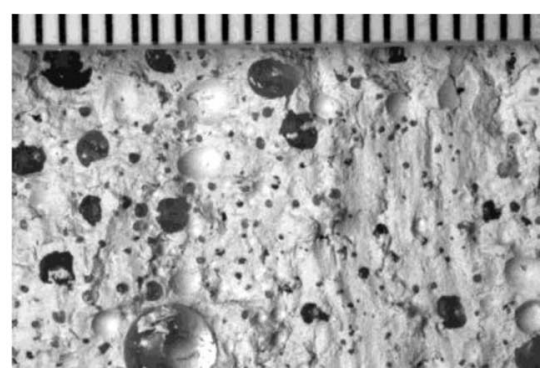

4-III

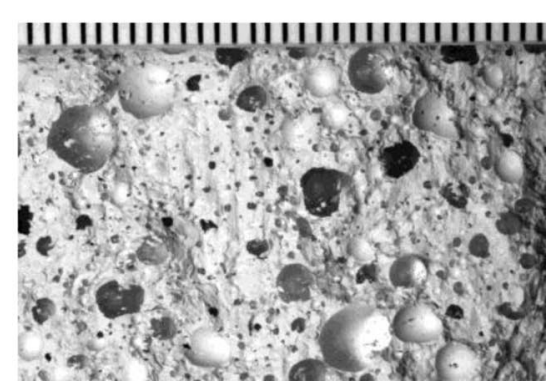

4-IV

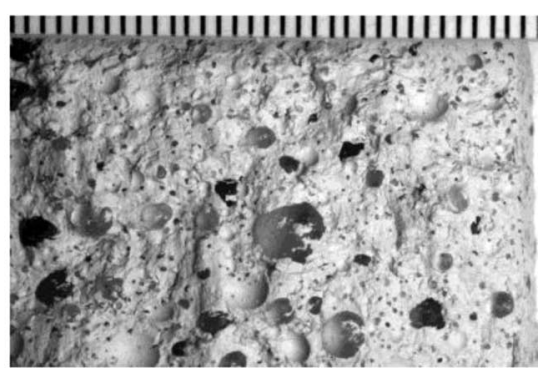

$4-\mathrm{V}$

Figure 5. Shear surfaces of tested specimens. See Table 2 for sample and test conditions. The graduated scale on the photographs is readable to $1.0 \mathrm{~mm}$ 


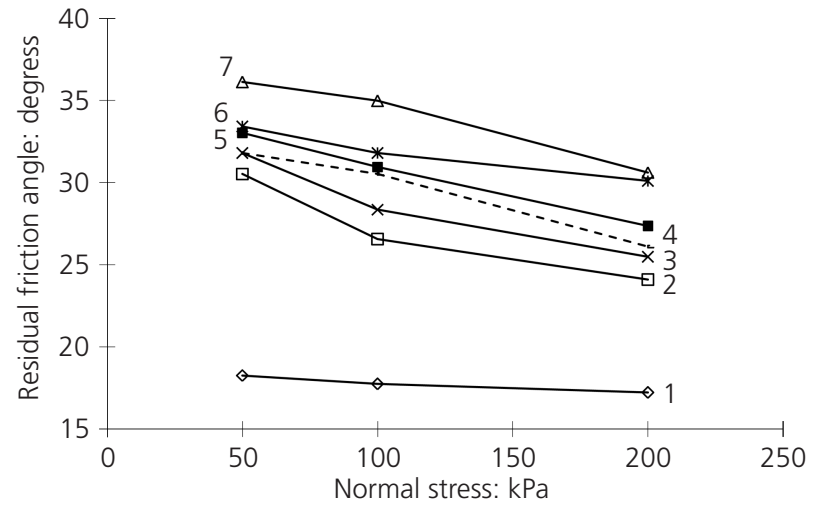

Figure 6. Reduction in residual friction angle with increase in normal stress

$(100 \mathrm{kPa})$ and 2-III, and it had the minimum residual shear strength correspondingly. Similarly, specimen 3-III had the lowest residual shear strength within the test set of specimens 3-I, 3-II and 3-III, and Specimen 4-III the lowest among specimens 4-I, 4-II and 4-III.

For soils with a high fines fraction, Stark and Eid (1994) argued that the stress-dependent behaviour of residual shear strength could be attributed to the rearrangement of platy clayey particles during shearing. They indicated that as the effective normal stress increases, the shear surfaces tend to be smooth (e.g. 2-III in Figure 5) as a result of the conversion of edge-to-face interactions of platy clay particles to face-to-face interactions, leading to a lower residual shear strength. For soils with a low fines fraction, Li and Aydin (2010) argued that, at a low normal stress, it is easy for coarse particles to overcome the resultant force induced by normal and shear stresses, and to ride over each other when they come into contact. In this case, slickensided shear surfaces can barely form, and the shear surfaces either have poorly developed and discontinuous slickensides (e.g. 3-I in Figure 5) or simply comprise a thick pile of materials (e.g. 4-I in Figure 5), leading to a high residual shear strength. At high normal stress, the coarse particles are pushed into the fine matrix when they come into contact, as the matrix is not sufficiently stiff to withstand the resultant force, introducing the accumulation of fine particles in the shear zone to cause a low residual shear strength (e.g. 4-III in Figure 5).

Figure 7 shows the residual friction angle determined for the specimens sheared under a normal stress of $200 \mathrm{kPa}$ at shearing rates of $0.06,0.6$ and $6.0 \mathrm{~mm} / \mathrm{min}$. Increasing the shearing rate from 0.06 to $6.0 \mathrm{~mm} / \mathrm{min}$ led to a decrease in residual shear strength for samples with a relatively greater fine fraction (samples 1 to 5), and an increase in residual shear strength for the coarser samples (samples 6 and 7). This indicates that there are two principal types of influence of shearing rate on soil behaviour: the increase or decrease in residual strength depends on the grain size distribution of the sample.

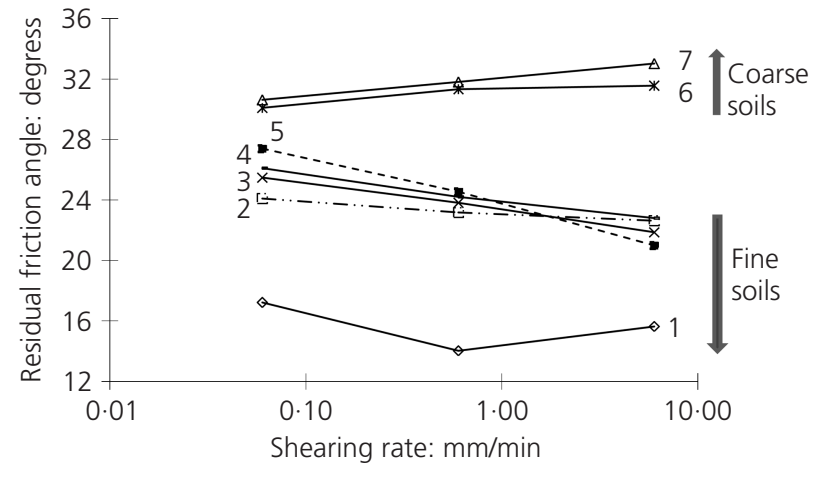

Figure 7. Shearing rate imposed positive and negative influences on coarse and fine soils respectively

For soils with a high fines fraction, the decrease in residual strength with increase in shearing rate is probably due to the development of excess pore water pressures as a result of contraction of the shear zone. Parathiras (1994) found that if the shearing rate is gradually decreased to a value that would allow for the dissipation of excess pore water pressure, the shear strength of the sample would increase. However, rapid shearing does not allow immediate dissipation of the excess pore water pressure generated during shearing. It is the delayed dissipation of pore pressure that reduces the residual shear strength.

With a small fines fraction, the sample did not develop any distinct shear surfaces, and behaved in a turbulent shear mode. The interlocking of coarse particles and reorientation of fine particles coexist in this situation. Lemos (1986) reported that a rapid shearing rate could cause a permanent disruption of the shear zone in which the fine particles have a lower degree of orientation, and that increasing the shearing rate could change the extent of reorientation and interlocking by weakening the former and enhancing the latter, leading to a rough shear surface and a high residual strength. Li and Aydin (2010) also indicated that, at a low shearing rate, the slow build-up of strong contact forces helps to anchor larger particles in place, and further compacts intermediate-sized particles as the coarse particles slide over them. This process eventually produces a relatively compacted shear zone and a relatively even shear surface, on which a low residual shear strength tends to be mobilised. On the other hand, at higher shearing rates, coarse particles would resist being pushed into the finer matrix, introducing more obstacles in the upper half of the specimen during relative movement, and causing a high residual shear strength.

\section{Conclusion}

Soils with a wide range of particle sizes are the most commonly encountered materials in geotechnical engineering practice. A systematic investigation into the constitutive behaviour of such soils was conducted by means of direct shear tests on artificial mixtures of kaolin and glass beads. The volume change and the structure and water content of the shear zone were methodically 
investigated. Based on the experimental results and analyses, the following conclusions can be drawn.

(a) A homogeneous soil specimen becomes heterogeneous after shearing. The shear zone is the most affected part of the specimen in terms of structure and void ratio, whereas these properties remain unchanged in the outer zones.

(b) The volumetric change of a specimen during shearing is consistent with variation of the water content in shear zone, indicating that the volumetric change of the specimen during shearing occurs primarily in the shear zone.

(c) The volume change and the structure of the shear zone are strongly dependent upon both the magnitude of normal stress applied and the shearing rate. A high normal stress and a low shearing rate tend to result in contraction, and smooth, well slickensided shear surfaces, while a low normal stress and a high shearing rate result in dilation and a rough shear surface.

(d) The residual friction angle decreases with an increase in the normal stress applied during shearing. A high shearing rate causes an increase in the residual shear strength for samples with low fine fraction, and reduces it in specimens with high fines fractions.

\section{Acknowledgements}

This research was partially supported by the Opening Fund of the State Key Laboratory of Geohazard Prevention and Geoenvironment Protection (Chengdu University of Technology) (Grant No. SKLGP2010K001), and the Opening Fund of the Key Laboratory of Karst Environment and Geohazard Prevention, Ministry of Education (Guizhou University) (Grant No. 2011-K01) and Key Project of Chinese Ministry of Education (Project No. 211656). The authors are deeply grateful to Dr Aydin Adnan for stimulating discussions on the research.

\section{REFERENCES}

Bernander S, Svensk I, Holmberg G, Bernander J and Isacsson K (1985) Shear strength and deformation properties of clays in direct shear tests at high strain rates. Proceedings of the 11th International Conference on Soil Mechanics and Foundation Engineering, San Francisco, CA, USA, vol. 2, pp. 987-990.

Chattopadhyay PK (1972) Residual Shear Strength of Some Pure Clay Minerals. PhD thesis, University of Alberta, Edmonton, Canada.

Cullen RM and Donald IB (1971) Residual strength determination in direct shear. Proceedings of the 1st Australia-NZ Conference on Geomechanics, Melbourne, Australia, vol. 1, pp. $1-10$.

De Beer E (1967) Shear strength characteristics of the 'Boom Clay'. Proceedings of the Geotechnical Conference, Oslo, Norway, vol. 1, pp. 83-88.

Garga VK (1970) Residual Shear Strength Under Large Strains and the Effect of Sample Size on the Consolidation of Fissured Clay. PhD thesis, University of London, UK.

Horn HM and Deere DU (1962) Frictional characteristics of minerals. Géotechnique 12(4): 319-335.
Hungr O and Morgenstern NR (1984) High velocity ring shear tests on sand. Géotechnique 34(3): 415-421.

Idriss IM (1985) Evaluating seismic risk in engineering practice. Proceedings of the 11th International Conference on Soil Mechanics and Foundation Engineering, San Francisco, CA, USA, vol. 1, pp. 255-320.

Kakou BG, Shimizu H and Nishimura S (2001) Residual strength of colluvium and stability analysis of farmland slope. Agricultural Engineering International: The CIGR Journal of Scientific Research and Development 3, http:// www.cigrjournal.org/index.php/Ejounral/issue/view/18.

Kenney TC (1967) Slide behaviour and shear resistance of a quick clay determined from a study of the landslide at Selnes, Norway. Proceedings of the Geotechnical Conference, Oslo, Norway, vol. 1, pp. 57-64.

La Gatta DP (1970) Residual Strength of Clays and Clay-Shales by Rotation Shear Tests. Harvard Soil Mechanics Series No. 86, Cambridge, MA, USA.

Lemos LJL (1986) The Effect of Rate of Shear on Residual Strength of Soil. PhD thesis, University of London, UK. Lemos LJL, Skempton AW and Vaughan PR (1985) Earthquake loading of shear surfaces in slopes. Proceedings of the 11th International Conference on Soil Mechanics and Foundation Engineering, San Francisco, CA, USA, vol. 4, pp. 1955-1962.

Li YR and Aydin A (2010) Behavior of rounded granular materials in direct shear: mechanisms and quantification of fluctuations. Engineering Geology 115(1-2): 96-104.

Lupini JF, Skinner AE and Vaughan PR (1981) The drained residual strength of cohesive soils. Géotechnique 31(2): 181213.

Martins JP (1983) Shaft Resistance of Axially Loaded Piles in Clay. PhD thesis, University of London, UK.

Mesri G and Shahien M (2003) Residual shear strength mobilized in first-time slope failures. Journal of Geotechnical and Geoenvironmental Engineering, ASCE 129(1): 12-31.

Mitchell JK (1993) Fundamentals of Soil Behavior, 2nd edn. Wiley, New York, NY, USA.

Parathiras AN (1994) Displacement Rate Effects on the Residual Strength of Soils. PhD thesis, University of London, UK.

Petley DJ (1966) The Shear Strength of Soils at Large Strains. $\mathrm{PhD}$ thesis, University of London, UK.

Sassa K (1985) The mechanism of debris flow. Proceedings of the 11th International Conference on Soil Mechanics and Foundation Engineering, San Francisco, CA, USA, vol. 3, pp. $1173-1176$.

Skempton AW (1985) Residual strength of clays in landslides, folded strata and the laboratory. Géotechnique 35(1): 3-8.

Skempton AW and Petley DJ (1967) The strength along structural discontinuities in stiff clay. Proceedings of the Geotechnical Conference on Shear Strength of Natural Soils and Rocks, Oslo, Norway, vol. 2, pp. 3-20.

Stark TD and Eid HT (1994) Drained residual strength of cohesive soils. Journal of Geotechnical and Geoenvironmental Engineering, ASCE 120(5): 856-871.

Suzuki M, Yamamoto T and Tanikawa K (2001) Variation in 
residual strength of clay with sharing speed. Memoirs of the Faculty of Engineering, Yamagushi University 52(1): 45-49. Tatsuoka F, Nakamura S, Huang CC and Tani K (1990) Strength anisotropy and shear band direction in plane strain tests of sand. Soils and Foundations 30(1): 35-56.

Taylor DW (1948) Fundamentals of Soil Mechanics. John Wiley, New York, NY, USA.

Tika TM (1989) The Effect of Fast Shearing on the Residual Strength of Soil. PhD thesis, University of London, UK.

Tika ThE and Hutchinson JN (1999) Ring shear tests on soil from the Vaiont landslide slip surface. Géotechnique 49(1): 59-74.

Townsend FC and Gilbert PA (1973) Tests to measure residual strengths of some clay shales. Géotechnique 23(2): 267-271. Townsend FC and Gilbert PA (1974) Engineering Properties of
Clay Shales, Report 2. Residual Shear Strength and Classification Indexes of Clay Shales. Soils and Pavements Laboratory, US Army Engineering Waterways Experiment Station, Vicksburg, MS, USA.

Wan YS and Kwong J (2002) Shear strength of soils containing amorphous clay-size materials in a slow-moving landslide. Engineering Geology 65(4): 293-303.

Wu PK, Matsushima K and Tatsuoka F (2008) Effects of specimen size and some other factors on the strength and deformation of granular soil in direct shear tests. Geotechnical Testing Journal, ASTM 31(1): 1-20.

Xu Z, Zhou G, Liu Z, Zhou J and Tian Q (2007) Correcting method and error analysis for sample area in direct shear test. Journal of China University of Mining and Technology 36(5): 658-662.

\section{WHAT DO YOU THINK?}

To discuss this paper, please email up to 500 words to the editor at journals@ice.org.uk. Your contribution will be forwarded to the author(s) for a reply and, if considered appropriate by the editorial panel, will be published as a discussion in a future issue of the journal.

Proceedings journals rely entirely on contributions sent in by civil engineering professionals, academics and students. Papers should be 2000-5000 words long (briefing papers should be 1000-2000 words long), with adequate illustrations and references. You can submit your paper online via www.icevirtuallibrary.com/content/journals, where you will also find detailed author guidelines. 